\title{
Penile-scrotal flap vaginoplasty versus inverted penile skin flap expanded with spatulated urethra: A multidisciplinary single-centre analysis
}

\author{
Giorgio Gentile $^{1}$, Ardigò Martino ${ }^{2}$, Daniela Nadalin ${ }^{3}$, Martina Masetti ${ }^{4}$, Brigida Lilia Marta ${ }^{5}$, \\ Franco Palmisano ${ }^{1}$, Alessandro Franceschelli ${ }^{1}$, Patrizia Stella ${ }^{3}$, Anna Paola Sanfelici ${ }^{3}$, \\ Eugenio Brunocilla ${ }^{4}$, Fulvio Colombo ${ }^{1}$ \\ ${ }^{1}$ Andrology Unit, University Hospital S.Orsola-Malpighi, Bologna, Italy; \\ ${ }^{2}$ Institute for Integrated Health, Federal University of Mato Grosso Do Sul, Campo Grande MS, Brazil; \\ ${ }^{3}$ Health Centre Gender Dysphoria at Movement for Transsexual Identity - Agreement with Local Health care Unit, City of Bologna, Italy; \\ ${ }^{4}$ Department of Urology, University of Bologna, Bologna, Italy; \\ ${ }^{5}$ Department of Anthropology, Medical Anthropology Research Center, Rovira I Virgili University, Tarragona, Spain.
}

\begin{abstract}
Summary This study is aimed to compare outcomes of penile-scrotal flap vaginoplasty to inverted penile skin flap expanded with spatulated urethra as a singlecentre experience.

Data regarding vaginoplasty performed between May 2003 and January 2014 were reviewed. Subjects were divided into two groups according to the surgical technique performed: perineal-scrotal flap vaginoplasty (Group A), and inverted penile skin flap expanded with spatulated urethra vaginoplasty (Group B). All patients underwent to psychological analysis before surgery. Functional follow-up was based on a modified validated Female Sexual Function Index. Overall, 67 patients with a mean $(S D)$ age of $34( \pm 9.38)$ years underwent to surgery. 41 patients were included into the Group $A$ and 26 into the Group B. Mean operative time among Groups A and B was $316( \pm 101.65)$ and $594( \pm 89.06)$ minutes, respectively $(p<0.0001)$. Longer postoperative hospitalization was shown in Group B (14 days $\pm 4,51)$ than in Group A (10 days $\pm 2,49)$; $(p<0.0001)$. Group B patients showed a higher anemization rate requiring blood transfusion $(p=0.00014)$ as well as compressive neuropathy ( $p=0.038$ ). In addition to this, necrosis of the skin flap was reported in 8 patients of Group B $(p<0.0001)$. Comprehensive functional follow-up data was included; spontaneous vaginal lubrication was not reported in $82.4 \%$ of Group A vs $12.5 \%$ cases of Group B ( $p=0.0085)$.

When compared to penile-scrotal flap vaginoplasty, inverted penile skin flap expanded with spatulated urethra technique shows an increased risk of complications with comparable satisfaction rates whereas a higher spontaneous vaginal lubrication is reported. Sexological support is of utmost importance in this setting.
\end{abstract}

KEY WORDS: Transgender; Penile inversion; Vaginoplasty; Techniques; Outcomes, Sexologist.

Submitted 2 March 2020; Accepted 16 March 2020

\section{INTRODUCTION}

The concept of "gender identity" (GI) in Male-to-Female people refers to the individual's awareness of belonging to female rather than to male gender (1). In this context, Stoller postulated the existence of GI distinguishing it from the "role identity", defined as the behavioral struc- ture of one gender rather than other within a specific social and cultural background (2-3).

The term GI disorder appeared in the DSM-IV in 1994 (4-5) and was renamed "gender dysphoria" (GD) in the 2013 DSM-V revised version (6), whereas biological sex ("feeling of being trapped in the wrong body") (7) is not perceived as wrong by patients but the gender assigned at birth. In the light of this, transsexualism treatment necessarily requires the change of the nominally assigned gender rather than sexual characters (6).

Besides being of utmost importance the psychological evaluation in GD diagnosis, patient should be managed in a multidisciplinary setting taking into account hormone replacement therapy, psychological support and, if required, sex reassignment surgery (SRS) (8).

Regarding the technical aspects of SRS, the principal surgical goal is the creation of aesthetically natural and functionally effective external female genitalia, with a sufficiently deep and compliant neovagina allowing normal sexual intercourse without anatomical hindrance (8).

In the 1950s, pioneers of SRS used invagination of the inverted penile skin sheath to form the neovagina, in order to maintain optimal vascularization (9).

Almost two decades later, Jones et al. described the principles of male-to-female (MTF) SRS using a double cutaneous flap obtained from penile, perineal and scrotal skin for the configuration of the neovagina (10).

This technique was the starting point for the development of several other procedures for MTF-SRS.

Particularly, Perovic et al. proposed to use a cylinder sharped by inverted penile skin widened with spatulated urethra for the neo-vaginal cavity's lining allowing an increased vaginal sensitivity with urethral secretionsrelated autonomous lubrication (11-12).

Since the comparison of the different techniques is still the subject of debate in relation to the different surgical outcomes particularly those related to complications and satisfaction rate, the aim to this study was to compare results of penile-scrotal flap vaginoplasty to inverted penile skin flap expanded with spatulated urethra as a single-centre experience. 


\section{Patients AND methods}

In this retrospective cohort study we identified patients within the Department of Andrology of our Centre who underwent vaginoplasty between May 2003 and January 2014. Patients were divided into two groups according the surgical technique performed: perineal-scrotal flap vaginoplasty (Group A), and inverted penile skin flap expanded with spatulated urethra vaginoplasty (Group B). For both groups, we recorded intraoperative features including, if present, a modification of the technique proposed by our Center for the creation of the mons veneris and of the neoclitoris, introduced from May 2010.

Before surgery, all patients underwent to psychological analysis performed by consultants working within the Transsexual Identity Movement (MIT), an Italian non-profit association that offers counselling assistance to transsexuals; this Service was created in 1994 acknowledging Emilia Romagna Government's financial support.

All patients were previously treated with estrogens and androgen antagonists and lived for at least two years in the role of a person belonging to the desired gender. Psychological aspects were recorded, such as the type of followed pathway, the observation of real-life experience, the examination of areas of the individual's global functioning such as the emotional, social and working areas and her defense mechanisms.

All patients underwent a detailed medical history intake, as well as a general physical and andrological examination. The procedure was performed by the same experienced surgical team.

Intraoperative and post-operative adverse events were recorded. Surgical complications were divided into three groups: intraoperative complications; short-term complications, noticed during the post-operative hospital stay; and long-term complications, noticed during follow up after patient discharge. Long-term complications were further divided according their aesthetical and functional concern.

Functional follow-up based on a standard internal protocol consisted of a modified validated Female Sexual Function Index (13-15), the questionnaire was administered through interviews during outpatient visits or by telephone to all the patients with at least 6 months of post-operative revaluation. This questionnaire was modified according to psychoclinical/sexological indications (see also supplementary file).

$\mathrm{R}$ software was used for statistical analysis ( $R$ : A language and environment for statistical computing; R Core Team, 2014; $R$ Foundation for Statistical Computing, Vienna, Austria). Statistical significance for the tests was set at $\alpha<.05$.

Descriptive statistics and test statistics were used to compare the 2 groups in terms of clinical variables. One-way Kolmogorov-Smirnov statistical tests were applied to assess the normality of variables. Continuous variables were presented as mean \pm standard deviation (SD) and compared using Chi squared, Fisher's exact and Wilcoxon tests, where normality could not to be assumed.

This retrospective study was conducted according to the guidelines and principles of the Declaration of Helsinki and standard ethical conduct for research involving humans; after approval of our Ethical Committee for Clinical Research, all patients signed an informed consent agreeing to supply their own anonymous data for this and future studies.

Table 1.

Surgical complications.

\begin{tabular}{|c|c|c|c|c|}
\hline Intra operative complications & Group A & Resolution & Group B & Resolution \\
\hline Rectum's injuries & $1(2.4 \%)$ & Simple suture & $1(3.9 \%)$ & Protective stoma recanalized after two months \\
\hline Anemization (calo di hb > 2 g) & $5(12.2 \%)$ & Transfusion & $14(53.8 \%)$ & Transfusion \\
\hline Bulbar urethra's injuries & $2(4.9 \%)$ & Simple suture & - & - \\
\hline Short-term post operative complications & Group A & Resolution & Group B & Resolution \\
\hline Hyperpyrexia ( $\mathrm{T}>38^{\circ} \mathrm{C}$ after the 4 th postoperative day) & $11(26.8 \%)$ & Antibiotic therapy & $13(50 \%)$ & Antibiotic therapy \\
\hline Anemization & $12(29.3 \%)$ & Transfusion & $20(76.9 \%)$ & Transfusion \\
\hline Compressive neuropathy & $3(7.3 \%)$ & Physiotherapy & $7(26.9 \%)$ & Physiotherapy \\
\hline Urethro-neovaginal fistula * & $1(2.4 \%)$ & Urinary catheter kept for 3 weeks & - & - \\
\hline Prolonged urethral bleeding & $1(2.4 \%)$ & Surgical revision & - & - \\
\hline Infection of the surgical wound associated with hyperpyrexia & $3(7.31 \%)$ & $\begin{array}{l}1 \text { Antibiotic therapy and } 1 \text { surgical } \\
\text { revision to remove necrotic material }\end{array}$ & - & - \\
\hline Clitoral ischemic necrosis & - & - & $1(3.9 \%)$ & Loss of clitoris \\
\hline Necrosis of the skin flaps with dehiscence of the wound sutures & - & - & $8(30.8 \%)$ & Courettage and sutures \\
\hline \multicolumn{5}{|l|}{ * Probably due to urethral necrosis. } \\
\hline Long-term postoperative complications & Group A & Resolution & Group B & Resolution \\
\hline Stenosis of the neo- urethral meatus & $5(12.2 \%)$ & Later meatoplasty & $1(3.9 \%)$ & Urinary catheter placed and maintained for two weeks \\
\hline Neovaginal atresia (reduction in vaginal depth up to less than $5 \mathrm{~cm}$ ) & $4(9.8 \%)$ & Enteric vaginoplasty (1/4 patients) & $2(7.7 \%)$ & Enteric vaginoplasty (1/2 patients) \\
\hline Vaginal prolapse & $1(2.4 \%)$ & Colpopexy & $1(3.9 \%)$ & - \\
\hline Recto-vaginal fistula $* *$ & - & - & $1(3.9 \%)$ & - \\
\hline \multicolumn{5}{|c|}{ ** The patient had previously undergone left hemicolectomy due to colorectal cancer followed by pelvic radiotherapy. } \\
\hline \multicolumn{3}{|l|}{ AESTETHICAL COMPLICATIONS } & Group A & Group B \\
\hline \multicolumn{3}{|c|}{ Reconfiguration of the labia majora due to asymmetries of them or to the presence of dog-ear residual. } & & - \\
\hline \multicolumn{2}{|c|}{ Clitoroplasty for a clitoral hypertrophy } & \multicolumn{2}{|c|}{$1(2.9 \%)$} & $2(\overline{7} .7 \%)$ \\
\hline \multicolumn{2}{|l|}{ Labia minora and/or clitoral hood's reconfiguration } & \multicolumn{2}{|c|}{$3(7.3 \%)$} & $1(3.9 \%)$ \\
\hline \multicolumn{2}{|l|}{ Lower neo-vaginal commissure's reconfiguration } & \multicolumn{2}{|c|}{$3(7.3 \%)$} & $1(3.9 \%)$ \\
\hline \multicolumn{2}{|l|}{ Scar tissues' removal } & \multicolumn{2}{|c|}{$2(4.9 \%)$} & - \\
\hline
\end{tabular}




\section{RESULTS}

Overall, 67 patients with a mean (SD) age of $34( \pm 9.38)$ years underwent to surgery. According to the technique performed, 41 patients were included into the Group A and 26 into the Group B. Our modified technique was applied to 26 subjects of Group A whereas was performed in all patients of Group B.

Mean (SD) operative time among Groups A and B was $316( \pm 101.65)$ and $594( \pm 89.06)$ minutes, respectively; this result was statistically significant $(p<0.0001)$. Similarly, postoperative hospitalization revealed longer in Group B (14 days \pm 4.51 ) than in Group A (10 days $\pm 2.49)$; $(p<0.0001)$. Surgical complications are reported in Table 1; Group B patients showed a higher blood transfusion rate $(p=0.00014)$ as well as compressive neuropathy ( $p=0.038)$. In addition to this, necrosis of the skin flap was reported in 8 patients of Group B $(\mathrm{p}<0.0001)$.

Functional questionnaire was administered in 19 subjects in Group A (46.3\%) and 17 patients in Group B $(65.4 \%) ; 46.3 \%$ of the whole cohort resulted unreachable or refused the questionnaire administration.

In terms of sexual orientation, 18 patients of Group A (94.7\%) declared to be mainly attracted to men and 1 (5.3\%) has defined herself as bisexual, while 14 (82.3\%) cases of Group B were mainly attracted to men, 1 was mainly attracted to women (5.9\%) and 2 were bisexual (11.8\%).

All patients with a stable partner, 12 (68.4\%) in Group A and $4(23.5 \%)$ in Group B, resulted to be attracted to men, and all their partners resulted to be attracted to women. Among Group A subjects with a stable relationship, $6(46.1 \%)$ reported to have sex once or twice a month, $6(46.1 \%)$ several times a week and 1 patient $(7,8 \%)$ daily.

Regarding Group B patients, 1 (25\%) reported to have sexual intercourses once or twice per month while 3 having sex $(75 \%)$ several times per week. Additionally, $61.5 \%$ of Group A (8) declared to be satisfied with their couple sexuality, 4 (30.8\%) revealed moderately satisfied whilst 1 case $(7.7 \%)$ demonstrated very dissatisfied with her couple sexuality.

Among Group B, 1 patient (25\%) declared to be very satisfied while $75 \%$ of cases (3) reported to be moderately satisfied with couple's sex life.

In terms of emotional complicity with the partner during sexual intercourse, 10 patients of group A (76.9\%) declared to be very satisfied and 3 patients (23.1\%) showed themselves moderately satisfied, while all 4 cases in Group B declared to be very satisfied about the couple emotional complicity.

Functional questionnaire results concerning autoerotism, sexual intercourses and sex arousal are reported in Table 2. When asked how often they managed to have a spontaneous vaginal lubrication during sexual activity, $82.4 \%$ of Group A answered to be never or almost never able to lubricate; significantly higher than 2 (12.5\%) cases of Group B ( $p=0.0085)$. In addition to this, $62.5 \%$ of Group B patients claimed to be able to lubricate always or most of the time.

Summarizing the overall sexual satisfaction in Group A and $\mathrm{B}$, patients defined as very satisfied in 10 and 11
Table 2.

Functional questionnaire investigating desire and sexual interest, frequency of sexual intercourses and masturbation, sex arousal.

\begin{tabular}{|c|c|c|}
\hline & Group A (n,\%) & Group B $(n, \%)$ \\
\hline \multicolumn{3}{|l|}{ How often do you masturbate? } \\
\hline Never & $12(63.1)$ & $5(29.4)$ \\
\hline Less than once a month & $1(5.3)$ & $2(11.8)$ \\
\hline One or two times a month & $2(10.5)$ & $4(23.5)$ \\
\hline Several times a week & $3(15.8)$ & $6(35.3)$ \\
\hline Daily & $1(5.3)$ & $\cdot$ \\
\hline \multicolumn{3}{|c|}{ How often do you have sexual intercourses? } \\
\hline Never & $3(15.8)$ & $2(11.8)$ \\
\hline Less than once a month & - & $2(11.8)$ \\
\hline One or two times a month & $8(42.1)$ & $4(23.5)$ \\
\hline Several times a week & $7(36.8)$ & $9(52.9)$ \\
\hline Daily & $1(5.3)$ & - \\
\hline \multicolumn{3}{|c|}{ Over the last 4 weeks how often have you felt sexual desire or sexual interest? } \\
\hline Always or almost always & $2(10.5)$ & $3(17.6)$ \\
\hline Often & $3(15.8)$ & $7(41.2)$ \\
\hline Sometimes & $10(52.6)$ & $7(41.2)$ \\
\hline Never or almost ever & $4(21.1)$ & - \\
\hline \multicolumn{3}{|c|}{ Over the past 4 weeks, how would you rate your level of sexual desire or interest? } \\
\hline Very high & $5(26.3)$ & $4(23.5)$ \\
\hline High & $5(26.3)$ & $4(23.5)$ \\
\hline Moderate & $5(26.3)$ & $9(53)$ \\
\hline Low & $1(5.3)$ & - \\
\hline Very low or none at all & - & - \\
\hline \multicolumn{3}{|c|}{$\begin{array}{l}\text { Over the past } 4 \text { weeks, how often did you feel sexually aroused ("turned on") during sexual activity } \\
\text { or intercourse? }\end{array}$} \\
\hline No sexual activity & $2(10.5)$ & $5(29.4)$ \\
\hline Almost always or always & $8(47.1)$ & $8(66.7)$ \\
\hline Most times (more than half the time) & $5(29.4)$ & $3(25)$ \\
\hline Sometimes (about half the time) & $3(17.6)$ & $1(8.3)$ \\
\hline A few times (less than half the time) & - & - \\
\hline Almost never or never & $1(5.9)$ & - \\
\hline \multicolumn{3}{|c|}{ How often did you reach orgasm through masturbation? } \\
\hline I don't masturbate & $5(26.3)$ & $3(17.6)$ \\
\hline Almost always or always & $5(26.3)$ & $10(71.4)$ \\
\hline Most times (more than half the time) & $1(7.1)$ & $1(7.1)$ \\
\hline Sometimes (about half the time) & $3(21.4)$ & $\cdot$ \\
\hline A few times (less than half the time) & $1(7.1)$ & - \\
\hline Almost never or never & $4(28.6)$ & $3(21.5)$ \\
\hline \multicolumn{3}{|c|}{ How often did you reach orgasm through sexual intercourses? } \\
\hline I don't have sexual intercourses & $1(5.3)$ & $1(5.9)$ \\
\hline Almost always or always & - & \\
\hline Most times (more than half the time) & $7(38.9)$ & $7(43.8)$ \\
\hline Sometimes (about half the time) & $2(11.1)$ & $4(25)$ \\
\hline A few times (less than half the time) & $5(28.7)$ & $2(12.5)$ \\
\hline Almost never or never & $4(22.2)$ & $3(18.8)$ \\
\hline \multicolumn{3}{|c|}{ Did you notice a change in the orgasmic feeling between before and after surgery? } \\
\hline Yes & $13(81.3)$ & $13(92.9)$ \\
\hline No & $3(18.8)$ & $1(7.1)$ \\
\hline I haven't had orgasm yet & $3(15.8)$ & $3(17.6)$ \\
\hline \multicolumn{3}{|c|}{$\begin{array}{l}\text { Over the past } 4 \text { weeks, how satisfied were you with your ability to reach orgasm during sexual } \\
\text { activity or intercourse? }\end{array}$} \\
\hline No sexual activity & $2(10.5)$ & $1(5.9)$ \\
\hline Very satisfied & $10(58.8)$ & $12(75)$ \\
\hline Moderately satisfied & $5(29.4)$ & $1(6.3)$ \\
\hline Moderately dissatisfied & $1(5.9)$ & $1(6.3)$ \\
\hline Very dissatisfied & $1(5.9)$ & $2(12.5)$ \\
\hline
\end{tabular}

( $52.6 \%$ vs. $64.7 \%$; p > 0.05) cases. Moreover 6 (31.6\%) patients of Group A declared to be moderately satisfied while $1(5.3 \%)$ was really dissatisfied, whereas in Group B 3 (17.6\%) patients were neither satisfied nor dissatis- 
Figure 1.

Supplementary data about post-operative problems.

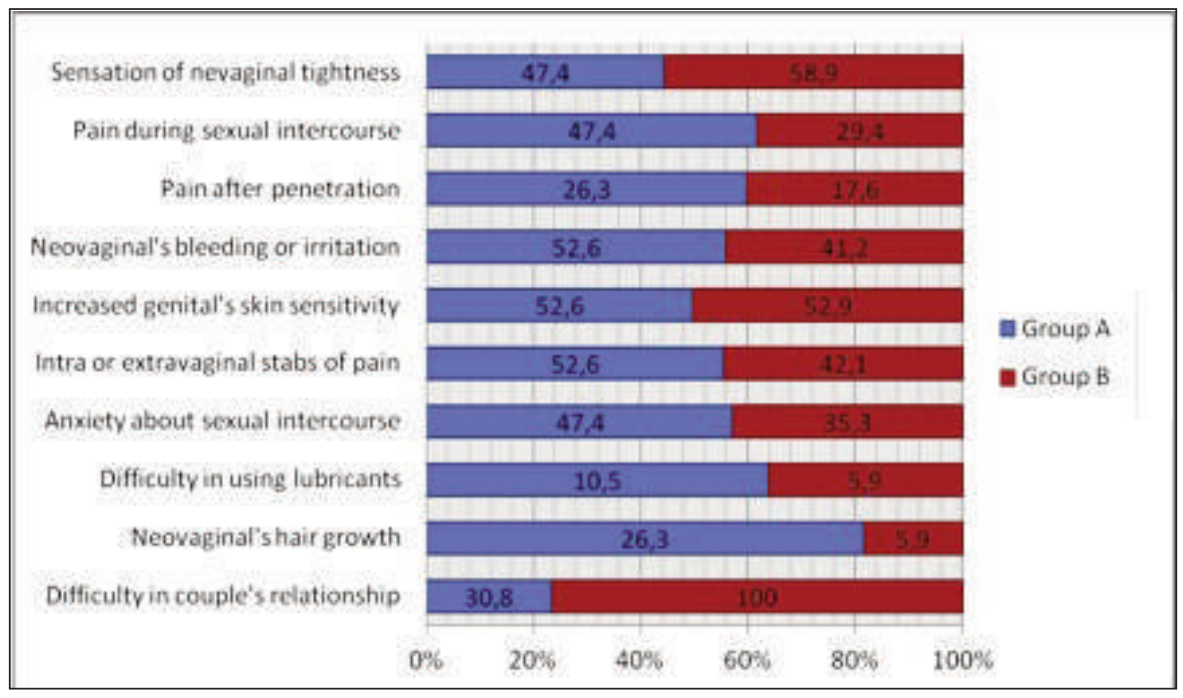

from issues in their sexual life to the point of requiring further surgery, whereas other patients with serious blemishes decide not to undergo re-intervention. Clitoral dimensions are inevitably related to original gland size, since the necessity of saving the marginal portion of the gland for vascularization and innervation of the neo-clitoris (20-21).

Moreover, depending on the surgical technique, the morphology of the lower commissure varies: Jones technique results in a u-shaped commissure while the Perovic strategy results in a v-shaped commissure, which has a more natural aspect and can allow hinder penetration (8). In our experi-

fied and 2 (11.8\%) declared to be moderately satisfied. Other post-operative problems revealed through questionnaire are reported in Figure 1.

\section{Discussion}

Vaginoplasty is often the final stage in the gender-confirming process for transgender women. Being gender affirmation surgery paramount in the treatment of gender dysphoria, vaginoplasty offers the opportunity for removal of masculine-appearing genitalia and replacement with a gender-congruent appearance (16).

The aim of our study was to compare two different techniques, from a surgical and functional point of view, in a cohort of transgender patients who underwent vaginoplasty, in the real-life setting. We found significant differences in terms of short-term adverse events with good aesthetic and functional results. In decades of experience at our Center, an original technical modification which involves the preservation of tunica albuginea below the neurovascular bundle was introduced in 2007, allowing a faster and safer clitoroplasty and providing a more natural aspect of mons veneris; this modification was adopted by Jones and subsequently by Perovic (17).

Outcomes of penile inversion vaginoplasty are generally in the form of large case series from high volume institutions. Buncamper et. Al reported a retrospective series of 475 patients who underwent penile inversion vaginoplasty, of whom $85 \%$ required additional full-thickness skin grafts (18). The most frequently observed intraoperative complication was rectal injury ( $\mathrm{n}=11-2.3 \%$ ) whereas short-term postoperative bleeding that required transfusion and/or reoperation was shown in $6.7 \%$ of the cohort. Among other vaginoplasty techniques, Salgado et al. reported a small case series of transwomen who underwent primary sigmoid vaginoplasty (19); among 12 patients, 2 major complications were reported (1 deep venous thrombosis, 1 suspected pulmonary embolism).

From an aesthetical and functional point of view, it is important to emphasize that imperfections are extremely subjective: women with minor imperfections may suffer ence, more patients within group A than group B were subjected to surgical reconfiguration of the lower commissure (7\% Group A - 3\% Group B): this may be dependent to an interindividual variability.

Concerning the sexual functionality and sensitivity evaluation, a different time lapse between two Groups should be taken into account. In fact, follow-up of the patients of Group A is longer than that of Group B, whereas the type B procedure has been performed in our Center only since 2010. This may significantly influence the quality of sexual life reported by patients: in fact, the capability of re-balancing personal sexuality on a different reproductive system and of reaching orgasm frequently requires a long period (22).

An important element which emerged from the questionnaire relates to the high ability to reach an autonomous vaginal lubrication after appropriate sexual stimulation in the patients of group B, due to the mucous secretions of the urethral flap that forms the neovaginal roof, confirming the data in Literature (11-12).

Stable partner was reported more commonly in Group A, this can be due to a longer follow-up, as well as by a quicker post-surgery recovery; in addition to this, the emerging trend in Group B concerning low sexual satisfaction may be related to the more challenging surgery and therefore to a longer process of integration of body parts with the symbolic expectations (23).

The widely shared results within two cohorts about the high emotional complicity of the couples during intercourse are likely motivated by issues due to stigma and prejudice as experienced by transsexual couples that, once overcome, tend to favor emotional sharing and lead to an increase of intimacy (24). Concerning the sexual desire levels, higher scores reported in the patient of Group B may be hypothetically due to their more consistent effort in post-surgery recovery phase and their interest into the expression of a sexual activity.

Neovaginal moisture is perceived by these patients as crucial, because it allows to be closer to a standard ideal of femininity, as it matches the symbolic component of 
representation with anatomical reality also in its functioning (25). Independently of the well-known benefits of SRS on the patients general and sexual life-related quality of life, as well as on cosmesis and sexual functioning $(26,31)$, it is reasonable to offer sexologic consultation in order to favor the integration of physical and anatomical parts and to sustain and encourage the subject undergoing surgery to achieve a satisfying sexuality. Several limitations to this study should be acknowledged, of which the single Institution design is probably the most evident. Another limitation of the present study lies in the fact that the two different types of intervention were performed by two different surgeons, and this may affect the data collected. On the other hand, this aspect is a good representation of a real-life situation in contrast to single surgeon series. In this context, regardless of the surgeon who performed surgery, it is important to consider that the longer duration of the surgical intervention, the longer post-surgery hospitalization and the higher rate of anemia and hyperpyrexia in the case of group B patients may be related to the greater technical complexity of this procedure, and to the fact that more vascularized tissues - such as the urethra - are handled. Moreover, the questionnaire used is not standardized; nevertheless, its essential purpose is to answer a purely surgical and clinical interest rather than to report objective measures of sexual satisfaction. In the light of this, there are more variables involved in sexual satisfaction compared to the biological subset, which is essentially linked to the type of surgery and its clinical consequences.

Therefore, the impact of body transformation on sexuality should be evaluated by qualitative methods, rather than quantitative, involving couples and not only individuals since that may interfere with subjective evaluation of surgery outcomes.

Lastly, it should be noted that this analysis focuses on an outdated case series; this is due to the fact that after 2014 the State funds destined for this setting were suspended; in this sense, we hope that this analysis will be a signal for the restoration of this public activity answering to a real need in the transgender community of our region.

\section{Conclusions}

When compared to penile-scrotal flap vaginoplasty, inverted penile skin flap expanded with spatulated urethra technique shows an increased risk of complications with a higher spontaneous vaginal lubrication and comparable satisfaction rates.

\section{REFERENCES}

1. Stoller RJ. Sex and gender. Vol.2: The transsexual experiment. London: Hogarth Press, 1975.

2. Stoller RJ. Presentations of gender. New Haven: Yale University Press, 1985.

3. Stoller RJ. The gender disorders. In: Rosen I, ed. Sexual deviations. Third Edition. Oxford: Oxford University Press, 1997.

4. American Psychiatric Association. Diagnostic and Statistical Manual of Mental Disorders, 4th ed. Washington, DC: APA, 1965.
5. American Psychiatric Association. Diagnostic and Statistical Manual of Mental Disorders. Fourth Edition, Text revision (DSM-IVTR). Washington, 2000.

6. American Psychiatric Association, Diagnostic and statistical manual of mental disorders (5 $5^{\text {th }} \mathrm{ed}$.) Arlington, 2013 VA: American Psychiatric Publishing.

7. Prosser J. Second skins: The body narratives of transsexuality. New York: Columbia University Press, 1998.

8. Belgrano E, Fabbris B, Trombetta C. Il Transessualismo, Identificazione di un Percorso Diagnostico e Terapeutico. Milano: ed. Kurtis 1999; 9-125.

9. Goddard JC, Vickery RM, Terry TR. Development of feminizing genitoplasty for gender dysphoria. J Sex Med. 2007; 4:981-9.

10. Jones HWJ, Schirmer HKA, Hoopes JE. A sex convention operation for males with transsexualism. Am J Obstet Gynecol. 1968; 100:101-9.

11. Perovic SV, Stanojevic DS, Djordjevic ML. Vaginoplasty in male transsexuals using penile skin and a urethra flap. BJU International. 2000; 86:843-850.

12. Perovic SV, Djinovic R. Genitoplasty in male-to-female transsexuals. Curr Opin Urol. 2009; 19:571-576.

13. Rosen R, Brown C, Heiman J, et al. The Female Sexual Function Index (FSFI): a multidimensional self-report instrument for the assessment of female sexual function. J Sex Marital Ther. 2000; 26:191-208.

14. Stephenson KR, Toorabally N, Lyons L, M Meston C. Further validation of the female sexual function index: specificity and associations with clinical interview data. J Sex Marital Ther. 2016; 42:448-61.

15. Roisin Worsley, Robin J. Bell, Pragya Gartoulla, and Susan R. Davis, Prevalence and predictors of low sexual desire, sexually related personal distress, and hypoactive sexual desire dysfunction in a community-based sample of midlife Women J Sex Med. 2017; 14:675-686.

16. Pariser JJ, Kim N. Transgender vaginoplasty: techniques and outcomes. Transl Androl Urol. 2019; 8:241-247.

17. Soli M, Brunocilla E. Male to female gender reassignment: Modified Surgical Technique for creating the clitoris and Mons Veneris. J Sex Med. 2008; 5:210-216.

18. Buncamper ME, van der Sluis WB, van der Pas RSD, et al. Surgical outcome after penile inversion vaginoplasty: a retrospective study of 475 transgender women. Plast Reconstr Surg. 2016; 138:999-1007.

19. Salgado CJ, Nugent A, Kuhn J, et al. Primary sigmoid vaginoplasty in transwomen: technique and outcomes. Biomed Res Int. 2018; 2018:4907208.

20. Giraldo F, Esteva I, Bergero T, et al. Corona glans clitoroplasty and urethropreputial vestibuloplasty in male-to-female transsexuals: the vulval aesthetic refinement by the Andalusia Gender Team. Plast Reconstr Surg. 2004; 114:1543-50.

21. Cocci A, Rosi F, Frediani D, et al. Male-to-Female (MtoF) gender affirming surgery: Modified surgical approach for the glans reconfiguration in the neoclitoris (M-shape neoclitorolabioplasty). Arch Ital Urol Androl. 2019; 91:119-124.

22. Bockting WO, Miner M, Robinson BE, et al. Transgender Identity Survey. 2005 Minneapolis, MN: University of Minnesota, Program in Human Sexuality. 
23. Feldman J, Safer J. Hormone therapy in adults: Suggested revisions to the sixth version of the standards of care. International Journal of Transgenderism. 2009; 11:146-182.

24. Van Trotsenburg MAA. Gynecological aspects of transgender healthcare. International Journal of Transgenderism. 2009; 11:238246.

25. Ruppin U, Pfäfflin F. Long-term follow-up of adults with gender identity disorder. Arch Sex Behav. 2015; 44:1321-1329.

26. De Cuypere G, T'Sjoen G, Beerten R, et al. Sexual and physical health after sex reassignment surgery. Arch Sex Behav. 2005; 34:679-690.

27. Gijs L, Brewaeys A. Surgical treatment of gender dysphoria in adults and adolescents: recent developments, effectiveness, and challenges. Annual review of sex research. 2007; 18:178-184.

28. Klein C, Gorzalka B. Sexual functioning in Transsexuals following hormone therapy and genital surgery: a review. J Sex Med. 2009; 6:2922-2939.

29. Marecek J, Crawford M, Popp D. On the construction of gender, sex, and sexualities. The psychology of gender. 2004; 2:192-216.

30. Bevan TE. The Psychobiology of Transsexualism and Transgenderism: A new view based on scientific evidence. Santa Barbara, CA: Praeger, 2015, p. 257 pp, ISBN-13: 978-1440831263.

31. Epstein S. A queer encounter: Sociology and the study of sexuality. Sociological Theory. 1994; 12:188-202.

\section{Correspondence}

Giorgio Gentile, MD

Franco Palmisano, MD (Corresponding Author)

franco.palmisano@hotmail.it

Fulvio Colombo, MD

Alessandro Franceschelli, MD

Andrology Unit, University Hospital S.Orsola-Malpighi,

via Pelagio Palagi 9, 40138 Bologna (Italy)

Ardigò Martino, MD

Institute for Integrated Health, Federal University of Mato Grosso Do Sul, Campo Grande MS (Brazil)

Daniela Nadalin, $M D$

Patrizia Stella, MD

Anna Paola Sanfelici, MD

Health Centre Gender Dysphoria at Movement for Transsexual Identity Agreement with Local Health care Unit, City of Bologna (Italy)

Martina Masetti, MD

Eugenio Brunocilla, MD

Department of Urology, University of Bologna, Bologna (Italy)

Brigida Lilia Marta, MD

Department of Anthropology, Medical Anthropology Research Center, Rovira I Virgili University, Tarragona, (Spain) 